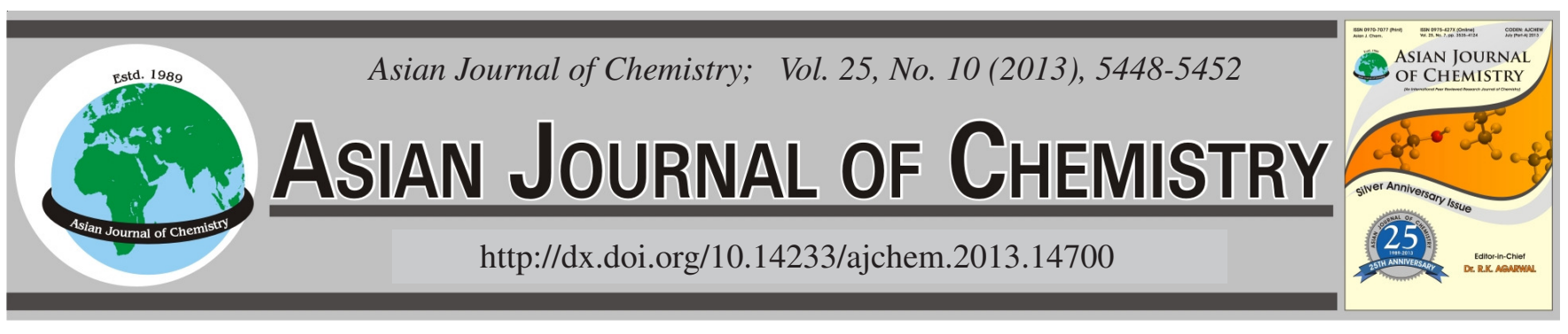

\title{
Antioxidant, Antibacterial and Antiproliferative Activities of Areal Parts of Swertia chirata (Bush Ham) Plant Extracts Using In Vitro Models
}

\author{
Syed Ali Raza Naqvi,"*, Qurat-Ul-Ain ${ }^{1}$, Zulfiqar Ali Khan $^{1}$, Zaib Hussain $^{2}$, \\ Sohail Anjum Shahzad ${ }^{3}$, Muhammad Yar ${ }^{4}$, Abdul Ghaffar ${ }^{1}$, Nasir Mahmood $^{5}$ and Samina Kousar ${ }^{2}$
}

\begin{abstract}
${ }^{1}$ Department of Chemistry, Government College University, Faisalabad-38000, Pakistan
${ }^{2}$ Institute of Chemistry, University of the Punjab, Lahore-54000, Pakistan

${ }^{3}$ Department of Chemistry, COMSATS Institute of Information Technology, Abbottabad-22060, Pakistan

${ }^{4}$ Interdisciplinary Research Center in Biomedical Materials, COMSATS Institute of Information Technology, Lahore-54000, Pakistan

${ }^{5}$ Department of Allied Health Sciences, University of Health Sciences, Lahore-54000, Pakistan
\end{abstract}

*Corresponding author: E-mail: a_naqvi313@yahoo.com

(Received: 17 October 2012;

Accepted: 11 April 2013)

AJC-13227

\begin{abstract}
Ariel parts of Swertia chirata was investigated for its medicinal values. Like many other plants and herbs, Swertia chirata has also been used for treating diseases particularly liver disorder. Anti-disease functions of most of the plants or herbs extracts have been associated with antioxidant and antibacterial potential. This study was performed to explore the antioxidant and antibacterial activity of the Swertia chirata (Bush ham). This was done by measuring possible constituents responsible for its antioxidant activity such as total phenolic and flavonoid contents. Antioxidant potential was measured using authentic in vitro assay models such as DPPH free radical scavenging assay and per cent inhibition of linoleic acid peroxide. The antibacterial and antiproliferative activity was measured against four different strains of gram positive and gram negative bacteria and MDBK cancer cell line, respectively. Promising concentration of total phenolics and flavonoids resulted encouraging DPPH free radical scavenging $(84.32 \pm 2.78$ and $82.54 \pm 3.12 \%)$ and linoleic acid peroxide inhibition $(94.04 \pm 4.23$ and $92.86 \pm 4.78 \%)$ and consequently credible antioxidant potential. Antibacterial and antiproliferative data of extracts indicated Swertia chirata might be a good member for fighting against infectious and chronic diseases.
\end{abstract}

Key Words: Antioxidants, Swertia chirata, HPLC, Antibacterial activity, Total phenolics, Free radical scavenging.

\section{INTRODUCTION}

The medicinal plants have a successful history to combat different chronic diseases. Plants contain a wide range of biological active compounds with great deal of interest in food, cosmetics and pharmaceutical industries. Due to no or lesser side effects of medicinal plant extracts, approximately 60-80\% of the world's population, especially in developing countries, still relies on folk medicines for the treatment of more than $87 \%$ common and serious illnesses ${ }^{1,2}$. Medicinal plants have a set of compounds that work together against the attack of disease causing factors. Most commonly these compounds behave directly or indirectly as antioxidants, antiinfection and anticancer agents.

Oxidative stress is considered to involve in key phenomena of living bodies. The stress is generated by different factors including reactive oxygen species (ROS). Reactive oxygen species and immune system both together attack to kill pathogens ${ }^{3}$. However, the common trend is that ROS, such as hydrogen per oxide, superoxide anion and hydroxyl radical that produce in living system are responsible for damaging cell structure, lipids, DNA and proteins ${ }^{4}$. Reactive oxygen species work through free radical chain mechanism which increase the risk of more than 30 different disease processes, including cancer ${ }^{5}$, stroke, Alzheimer's disease ${ }^{6}$, heart diseases ${ }^{7}$, Parkinson's disease $(\mathrm{PD})^{8}$, Schizophrenia ${ }^{9}$, arteriosclerosis ${ }^{10}$ etc. Naturally occurring antioxidants have strong and effective mechanism to scavenge these species.

Pakistan has great diversity in seasons in different areas and also has world's rich land of naturally occurring flora. The diversity in seasons, through out the year imparts very useful change in biological active constituents in plants. Most of the herbs indigenous to Pakistan are being used to manage oxidative stress and infectious diseases. Very promising ratio of medicinal and biological active constituents in medicinal plants play golden role to treat those pathogenic infections which have shown resistance to synthetic antibiotics. This might be the reason that leading medicinal research groups are actively engaged for revaluing antioxidant and antimicrobial activities of plants and herbs indigenous to their countries. 
Swertia chirata (Fig. 1) belong to family Gentianaceae, which is considered of great traditional medicinal values. The plant is indigenous to temperate Himalaya. The entire plant is considered medicinally important particularly roots. The extract of this plant is being used in number of herbal medicines ${ }^{11}$ as antihypoglycaemic, antifungal, antipyretic and antiinfectant ${ }^{1}$. Despite a descent hold in the herbal industry, insufficient research has been undertaken to explore its antioxidant, antimicrobial and anticancer values. Further it is also not clear whether the plant behaves differently with varying climatic conditions or genotypes.

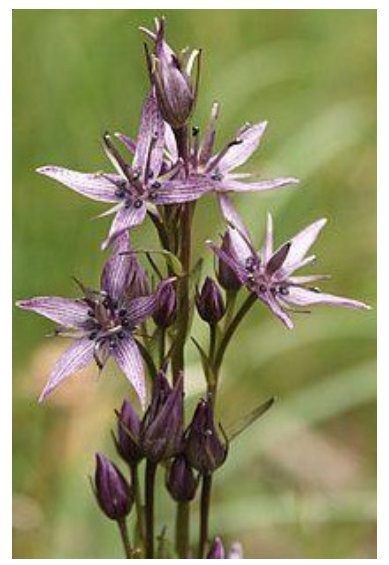

Fig. 1. Areal parts of the Swertia chirata plant

The focus of this study was to investigate the antioxidant, antimicrobial and anticancer potential of methanolic and ethanolic extracts of Swertia chirata collected from northern areas of Pakistan. The antioxidant activity was determined by estimating total phenolic contents, total flavonoid contents and using different free radical scavenging assays. The antimicrobial and anticancer study was done against four different bacterial strains and MDBK cancer cell line.

\section{EXPERIMENTAL}

Methanol, ethanol, ethyl acetate (extra pure) were purchased from sigfrom/merk. Water was twice distilled and filtered (FH$0.45 \mathrm{~lm}$, Advantec MFS Inc., Japan) using a decompressing pump (Division of Millipore, Waters, USA). 2,2-Diphenyl-1picrylhdrazil (DPPH), ascorbic acid (vitamin C), Folin-Ciocalteu reagent, butylated hydroxytoluene (BHT), gallic acid, butylated hydroxy anisole (BHA) and all phenolic standards were purchased from Sigma-Aldrich chemical Co. A Millipore type filter (pore size 0.22 and $0.45 \mu \mathrm{m}$ ) was obtained from Sartorius, USA. Absorption in UV-visible range of samples was measured using double beam U-2800 UV-visible spectrometer, HITACHI, Japan. Bacterial strains and MDBK cancer cell line was obtained from University of Health Sciences, Lahore.

Plant materials: The complete plants were collected from northern areas of Pakistan and identified at the Botany Department, Government College University, Faisalabad. Voucher Specimens were deposited at the Department of Botany, Government College University, Faisalabad.

Preparation of plant sample and extraction: Leave, stems and flowers after cleaning with distilled water dried at normal room temperature. The dried plants were chopped into small pieces and ground to fine homogenous powder with electrical blender (National®, Japan). The fine homogenous plant powder was soaked and shaked for $6 \mathrm{~h}$ at orbital shaker either in $95 \%$ ethanol or $80 \%$ methanol at room temperature. The mixture was then filtered using whatman 1 filter paper and the supernatant was then subjected to rotary evaporator (EYELA, N-N Series, Rikakikai Co. Ltd. Tokoyo, Japan) to evaporate the solvent at $40^{\circ} \mathrm{C}$. The dried supernatant was then stored in refrigerator at $4{ }^{\circ} \mathrm{C}$ till further analysis.

Total phenolic content (TPC): Amount of total phenolic content was calculated using Folin-Ciocalteu reagent as described by Chaovanalikit and Wrolstad ${ }^{12}$ with slight modification. Briefly, $1 \mathrm{~mL}$ of extract solution $(0.05 \mathrm{~g} / \mathrm{mL}$ ethanol $)$ was mixed with $200 \mu \mathrm{L}$ of Folin-Ciocalteu reagent and $3 \mathrm{~mL}$ deionized water and the mixture was kept at room temperature for $10 \mathrm{~min}$ and then $0.75 \mathrm{~mL}$ of $20 \%$ sodium carbonate (w/v) was added. The mixture was heated in a water bath at $40{ }^{\circ} \mathrm{C}$ for $20 \mathrm{~min}$ and then cooled in an ice-bath. Finally absorbance was taken at $755 \mathrm{~nm}$. Amount of total phenolic content was calculated using a calibration curve for gallic acid (10-130 ppm). The results were expressed as gallic acid equivalents (GAE) g/100 g dry extract matter. Sample was analyzed thrice and results were averaged.

Total flavonoid content (TFC): Total flavonoid content was determined following the procedure by Dewanto et al..$^{13}$. One milliliter of extract solution containing $0.01 \mathrm{~g} / 1 \mathrm{~mL}$ of dry matter was placed in a $10 \mathrm{~mL}$ volumetric flask and then $5 \mathrm{~mL}$ of distilled water was added followed by $0.3 \mathrm{~mL}$ of $5 \%$ $\mathrm{NaNO}_{2}$. After $5 \mathrm{~min}, 0.6 \mathrm{~mL}$ of $10 \% \mathrm{AlCl}_{3}$ was added and for another 5 min interval, $2 \mathrm{~mL}$ of $1 \mathrm{M} \mathrm{NaOH}$ was added and volume was made up to mark with distilled water. Absorbance was measured at $510 \mathrm{~nm}$. Total flavonoid concentration was expressed as catechin equivalents g/100 g of dry matter. Sample was analyzed thrice and results were averaged.

Free radical scavenging activity: Free radical scavenging activity of extracts was assessed according to the method reported by Bozin et al. ${ }^{14}$. Sample solution of dried extract was made by dissolving $0.01 \mathrm{~g}$ in $10 \mathrm{~mL}$ methanol. Took equal volume of sample solution and $90 \mu \mathrm{M}$ DPPH solution $(2 \mathrm{~mL}$ of each) to make a $4 \mathrm{~mL}$ stock solution. Stock solution was then put in dark for $0.5 \mathrm{~h}$. Blank solution was made by mixing $2 \mathrm{~mL}$ of $90 \mu \mathrm{M}$ DPPH solution in $2 \mathrm{~mL}$ of methanol. The absorbance at $515 \mathrm{~nm}$ of the resulting solutions and the blank were recorded at room temperature using a spectrophotometer (U-2001, Hitachi Instruments Inc. Tokyo, Japan). Butylated hydroxytoluene (BHT) was used as a positive control. For each sample, three replicate absorbance data was recorded. Per cent scavenging of DPPH free radical was calculated using following formula:

$$
\text { Scavenging }(\%)=\left(\frac{\mathrm{A}_{\text {Blank }}-\mathrm{A}_{\text {Sample }}}{\mathrm{A}_{\text {Blank }}}\right) \times 100
$$

Per cent inhibition in linoleic acid system: The antioxidant potential of Swertia chirata extracts was determined in terms of measurement of per cent inhibition of peroxidation in linoleic acid system ${ }^{15}$. To a solution mixture of linoleic acid $(0.05 \mathrm{~mL}), 99 \%$ ethanol $(4 \mathrm{~mL})$ and $4 \mathrm{~mL}$ of $0.1 \mathrm{M}$ sodium phosphate buffer ( $\mathrm{pH} 7$ ), $2 \mathrm{mg}$ dried plant extract was added 
and total mixture was diluted to $10 \mathrm{~mL}$ with distilled water. The solution was incubated at $40^{\circ} \mathrm{C}$. The degree of oxidation was measured following the thiocyanate ion method ${ }^{16}$. Briefly, $10 \mathrm{~mL}$ of ethanol (75\%; v/v), $0.2 \mathrm{~mL}$ of an aqueous solution of ammonium thiocyanate (30\%), $0.2 \mathrm{~mL}$ of sample solution and $0.2 \mathrm{~mL}$ of ferrous chloride $\left(\mathrm{FeCl}_{2}\right)$ solution $(20 \mathrm{mM}$ in 3.5 $\% \mathrm{HCl} ; \mathrm{v} / \mathrm{v})$ were added sequentially. After $3 \mathrm{~min}$ of stirring, the absorption values of mixtures measured at $500 \mathrm{~nm}$ were taken as peroxide contents. Synthetic antioxidants; butylated hydroxytoluene (BHT) was used as a positive control. The minimum peroxidation level of blank was observed at $75 \mathrm{~h}$ (3 days) time point that contained no antioxidant component (used as a test point). Per cent inhibition of linoleic acid per oxidation (I \%) was calculated using following relation:

Inhibition (\%)

$$
=\left[100-\left(\frac{\text { Abs. increase of sample at } 75 \mathrm{~h}}{\text { Abs. increase of control at } 75 \mathrm{~h}}\right) \times 100\right]
$$

Antibacterial assay: The antibacterial potential of Swertia chirata methanolic and ethanolic extracts was measured as described earlier Nasir et al. ${ }^{17}$. The liquid cultures of four bacterial strains $(100 \mu \mathrm{L})$ with optical density $(\mathrm{OD})$ value 1.41.6 at $600 \mathrm{~nm}$ were used to inoculate $10 \mathrm{~mL} \mathrm{LB}$ broth medium containing 12.5, 25, 37.5, 50 and $0 \mu \mathrm{g}$ (as control) of each extract. All tubes containing bacterial cultures and extracts were incubated for $24 \mathrm{~h}$ at $37^{\circ} \mathrm{C}$. The bacterial growth inhibition was measured by taking optical density at $600 \mathrm{~nm}$.

Antiproliferative assay: The antiprolifeartive bioassay was carried as described earlier Mosmann ${ }^{18}$. MDBK cell line was used for assay and extracts were diluted five folds in labelled wells while maintaining the cell number constant in each well of 96-wells plate i.e., 2000 cells/well. GMEM medium was used for the growth of cells amended with $5 \%$ FBS and $5 \% \mathrm{CO}_{2}$ supply while incubating at $37{ }^{\circ} \mathrm{C}$ for $48 \mathrm{~h}$. After incubation added $20 \mu \mathrm{L}$ of 3-[4,5-dimethylthiazol-2-yl]2,5-diphenyltetrazolium bromide (MTT) stock solution of concentration $5 \mathrm{mg} / \mathrm{mL}$. The plate was again placed in $5 \%$ $\mathrm{CO}_{2}$ incubator at $37^{\circ} \mathrm{C}$ for $3 \mathrm{~h}$ for the formation of crystals of purple formazan. Then Added $100 \mu \mathrm{L}$ of DMSO in each well to dissolve the crystals and OD value was measured at 570 $\mathrm{nm}$ with reference to control. Experiments were repeated thrice to obtain mean values.

\section{RESULTS AND DISCUSSION}

Per cent yield: Extraction in $80 \%$ methanol and ethanol revealed methanol is more favourable solvent for improving per cent yield of compounds of interest. Twenty per cent increase in yield was noted with methanol $(10.3 \mathrm{~g} / 100 \mathrm{~g}$ dried plant sample) solvent was used as compared to ethanol (8.3 $\mathrm{g} / 100 \mathrm{~g}$ dried plant sample).

Total phenolic and flavonoid contents: Both, methanolic and ethanolic extracts were subjected to estimate phenolics and flavonoids. Phenolics or polyphenolics are considered to involve in various biological defence i.e. as an antioxidant, antiatherogenic, antiproliferative, antimutagenic and cardioprotective vectors ${ }^{19-25}$. Fruits, cereals and vegetables contain effective amount of polyphenolics and are extensively used to combat oxidative stress diseases and pathogenic infections ${ }^{26,27}$.
Total phenolics found in methanolic extract was higher (272.67 $\pm 5.09 \mathrm{mg}$ gallic acid equivalents/g of dry weight extract of Sewertia chirata) than obtained using ethanol $(189.20 \pm 3.98 \mathrm{mg}$ gallic acid equivalents/g of dry weight extract of Sewertia chirata) and same trend in concentration was observed while estimating total flavonoids i.e., $3.38 \pm$ $0.56 \mathrm{mg}$ catechin equivalents/g of dry weight of Sewertia chirata and $3.17 \pm 0.31 \mathrm{mg}$ catechin equivalents/g of dry weight of Sewertia chirata, respectively (Table-1). Yue et al. ${ }^{25}$ reported antioxidant study of ethanolic extract of Swertia chirata. They reported approximately similar contents of phenolics and flavonoids.

TABLE-1

PER CENT YIELD, TOTAL PHENOLIC CONTENTS

AND TOTAL FLAVONOID CONTENTS OF METHANOLIC AND ETHANOLIC EXTRACTS OF Swertia chirata

\begin{tabular}{ccccc}
\hline $\begin{array}{c}\text { S. } \\
\text { No. }\end{array}$ & $\begin{array}{c}\text { Swertia } \\
\text { chirata } \\
\text { Extract }\end{array}$ & Yield (\%) & $\begin{array}{c}\text { Total phenolic } \\
\text { contents (TPC) } \\
(\mathrm{g} / 100 \mathrm{~g})\end{array}$ & $\begin{array}{c}\text { Total flavonoid } \\
\text { contents (TFC) } \\
(\mathrm{g} / 100 \mathrm{~g})\end{array}$ \\
\hline 1 & Methanolic & $10.45 \pm 1.08$ & $27.2 \pm 2.84$ & $3.38 \pm 0.23$ \\
2 & Ethanolic & $8.23 \pm 1.12$ & $18.9 \pm 2.43$ & $3.17 \pm 0.19$ \\
\hline
\end{tabular}

Means of three replicates \pm SD (standard deviation).

Antioxidant behaviour of the extracts: Fig. 2 expresses the promising scavenging of DPPH free radical. DPPH is a stable free radical that has commonly been used to test the antioxidant potential of natural extracts. The antioxidant property of the natural product is evaluated by measuring the decrease in absorbance power of DPPH on addition of particular concentration of antioxidant test sample. The two parameters, absorbance and the antioxidant activity, are inversely proportional to each other. Methanolic and ethanolic extracts of areal parts of the plant having concentration $200 \mu \mathrm{g} / \mathrm{mL}$ were showed significant inhibition of DPPH free radical i.e., $84.32 \pm 2.78$ and $82.54 \pm 3.12 \%$, respectively while at the same concentration of standard (BHT) showed $93.72 \pm 3.22 \%$ inhibition. At the same concentration of aqueous extract of Swertia chirata, Vivek et al. ${ }^{5 a}$ reported $59.80 \%$ scavenging of DPPH free radical.

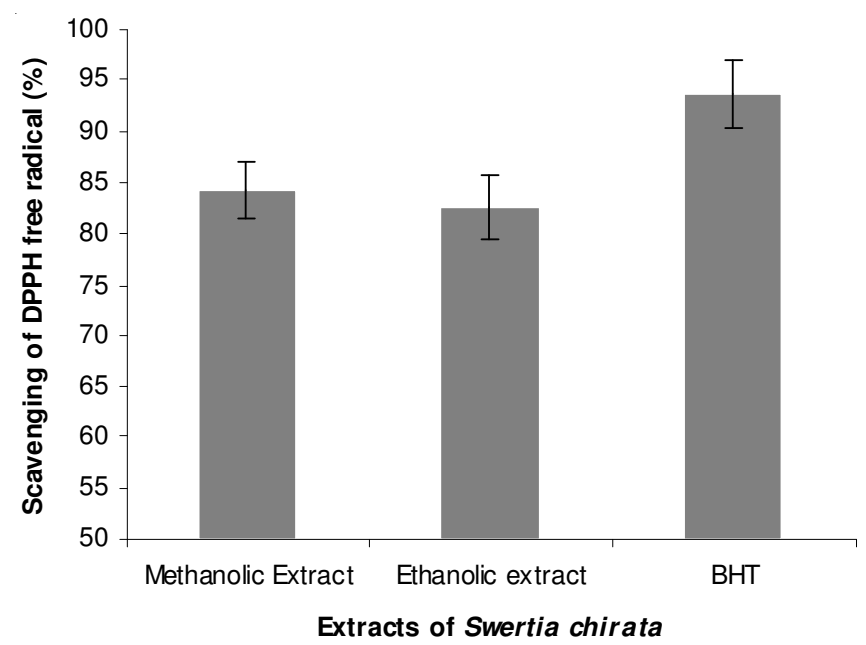

Fig. 2. Methanolic and ethanolic Swertia chirata extract potential to scavenge DPPH free radical 
Inhibition of linoleic acid peroxidation assay was also used to evaluate the antioxidant activity of the test sample. Fig. 3 shows the results obtained by this assay. Linoleic acid is a poly unsaturated fatty acid, upon oxidation, peroxide are formed which oxidized $\mathrm{Fe}^{2+}-\mathrm{Fe}^{3+}$ ions. The later state of peroxides form complex with thiocyanate ions. The intensity of the coloured complex is measured at $500 \mathrm{~nm}$. Per cent inhibition of linoleic acid peroxidation of methanolic and ethanolic extract was measured $94.04 \pm 4.23$ and $92.86 \pm 4.78$ $\%$, respectively. Anyhow, standard BHT showed $97.81 \pm 3.07$ $\%$ for the same concentration.

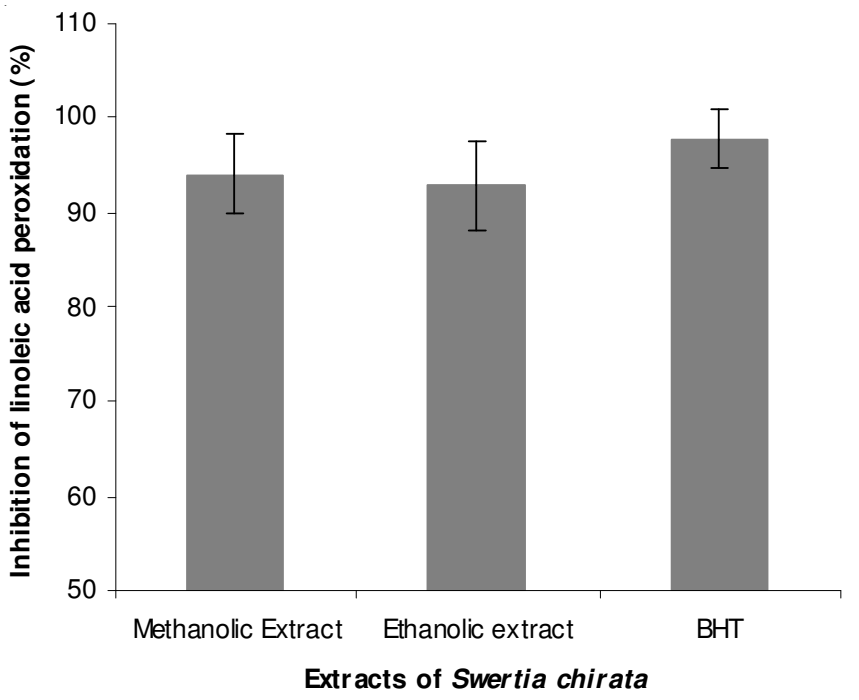

Fig. 3. Methanolic and ethanolic Swertia chirata extract potential to inhibit the linoleic acid peroxidation

Antibacterial study of extracts: Methanolic and ethanolic extracts of Swertia chirata showed strong antibacterial potential with increased concentration from 0-50 $\mu \mathrm{g}$ against two bacterial species viz., Streptococcus sp. and E. coli. Maximum reduction of bacterial growth was observed at $50 \mu \mathrm{g}$ concentration with reference to control $(0 \mu \mathrm{g})$ devoid of any extract. In case of Bacillus sp. and Staphylococcus sp. no any significant decline in bacterial growth was observed as was in case of other two bacterial strains (Table-2). These results are in agreement with Ganjewala et al. ${ }^{28}$ and Shinwari et al. ${ }^{29}$ who reported the same facts while working on extract of Lantana camara and Justicia adhatoda while Joshi and Dhawan ${ }^{11}$ also reported the microbial growth inhibition potential of aqueous extract of Swertia chirayita.
Antiproliferative potential of extracts: The antiprolifeartive assays of methanolic and ethanolic extracts of Swertia chirata were carried out by using MDBK cell line in order to explore the anticancerous potential of these extracts. Both extracts have not shown significant effect regarding inhibition of cancerous cells growth with reference to control which was devoid of plant extract (Fig. 4). The current study depicts the direct effect of both extracts on MDBK cells whose growth was not inhibited in response to these extracts which was not in agreement with Saha et al. ${ }^{30}$ who reported the anticancerous effect of Swertia chirata by using mouse model.

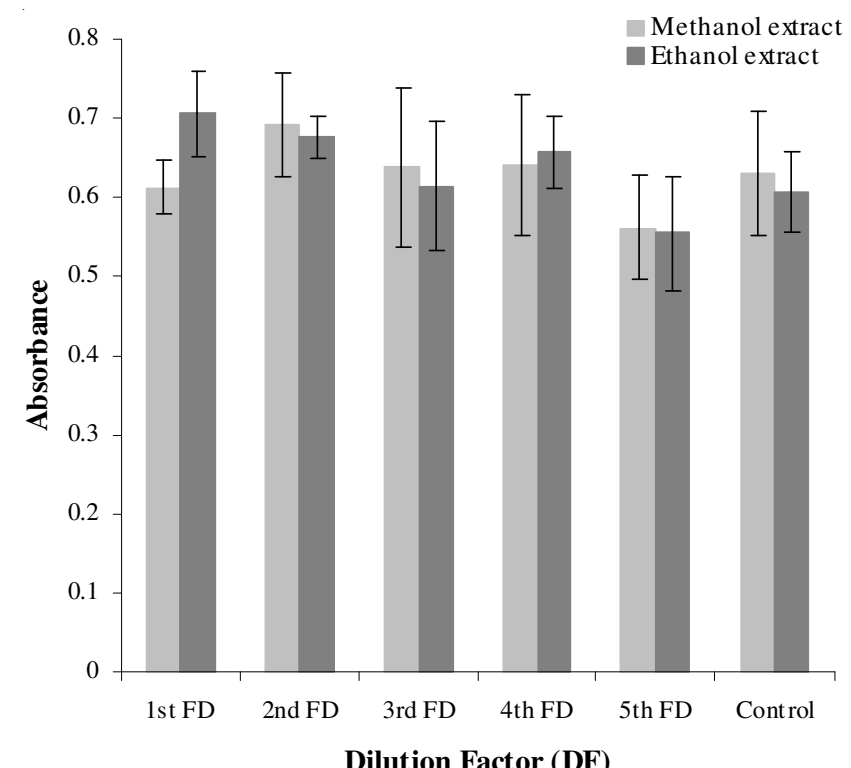

Fig. 4. Antiproliferative assay of methanolic and ethanolic extracts of Swertia chirata

\section{Conclusion}

There is a strong correlation among polyphenolics, flavonoids and antioxidant property. It also has been reported many times that if a plant has antioxidant potential possibly will carry antibacterial potential. Methanolic and ethanolic extracts of the areal parts of Swertia charata showed significant antioxidant activity. Methanolic extract was slightly more active as compared to ethanolic extract to inhibit oxidation process. However, regarding antibacterial potential both extract showed promising inhibition of Streptococcus sp. and E. coli growth while in case of Bacillus sp. and Staphlococuss sp., it

\begin{tabular}{|c|c|c|c|c|c|}
\hline \multicolumn{6}{|c|}{$\begin{array}{l}\text { TABLE-2 } \\
\text { rY OF METHANOLIC AND ETHANOLIC } \\
\text { RT OF Swertia chirata } \text { PLANT EXTRACTS }\end{array}$} \\
\hline Microorganism & $0 \mu \mathrm{g}$ & $12.5 \mu \mathrm{g}$ & $25 \mu \mathrm{g}$ & $37.5 \mu \mathrm{g}$ & $50 \mu \mathrm{g}$ \\
\hline \multicolumn{6}{|c|}{ Swertia chirata methanolic extract } \\
\hline Bacillus sp. & $2.1 \pm 0.10$ & $1.63 \pm 0.21$ & $2.41 \pm 0.32$ & $1.34 \pm 0.16$ & $1.06 \pm 0.13$ \\
\hline Staphylococcus sp. & $1.9 \pm 0.15$ & $1.89 \pm 0.19$ & $2.16 \pm 0.27$ & $1.12 \pm 0.09$ & $1.23 \pm 0.10$ \\
\hline Streptococcus sp. & $2.4 \pm 0.09$ & $2.37 \pm 0.28$ & $1.80 \pm 0.11$ & $1.10 \pm 0.15$ & $0.42 \pm 0.07$ \\
\hline E. coli & $2.5 \pm 0.11$ & $2.22 \pm 0.22$ & $1.65 \pm 0.18$ & $1.24 \pm 0.17$ & $0.86 \pm 0.11$ \\
\hline \multicolumn{6}{|c|}{ Swertia chirata ethanolic extract } \\
\hline Bacillus sp. & $2.1 \pm 0.10$ & $1.75 \pm 0.13$ & $1.56 \pm 0.21$ & $1.50 \pm 0.21$ & $1.33 \pm 0.25$ \\
\hline Staphylococcus sp. & $1.9 \pm 0.15$ & $2.05 \pm 0.20$ & $2.42 \pm 0.24$ & $1.41 \pm 0.15$ & $1.05 \pm 0.14$ \\
\hline Streptococcus sp. & $2.4 \pm 0.09$ & $2.38 \pm 0.19$ & $1.71 \pm 0.13$ & $1.23 \pm 0.11$ & $0.62 \pm 0.09$ \\
\hline E. coli & $2.5 \pm 0.11$ & $2.45 \pm 0.24$ & $1.82 \pm 0.16$ & $1.41 \pm 0.14$ & $0.83 \pm 0.18$ \\
\hline
\end{tabular}


was unable to inhibit growth prominently. Antiproliferative study results of Swertia chirata extracts against MDBK cancer cell line also not encouraging. It is therefore concluded that methanolic and ethanolic extracts of Swertia chirata could be used against oxidative stress diseases and bacterial infections.

\section{ACKNOWLEDGEMENTS}

The authors gratefully acknowledged Higher Education Commission (HEC) of Pakistan for providing research grant under the project No. PM-IPFP/HRD/HEC/2011/0007 under IPFP/TTS program.

\section{REFERENCES}

1. W.H. Carmen, Anal. Bioanal. Chem., 373, 23 (2002).

2. A.M. Saab, R. Tundis, M.R. Loizzo, I. Lampronti, M. Borgatti, R. Gambari, F. Menichini, F. Esseily and F. Menichini, Nat. Prod. Res., 26, 1741 (2012).

3. A.W. Segal, Ann. Rev. Immunol., 23, 197 (2005).

4. B. Halliwell, Biochem. J., 401, 1 (2007).

5. (a) R.V. Kumar, K. Satish, S. Shashidhara, S. Anitha and M. Manjula, Int. J. Pharm. Sci. Drug Res., 3, 48 (2011); (b) M. Valko, D. Leibfritz, J. Moncol, M.T.D. Cronin, M. Mazur and J. Telser, Int. J. Biochem. Cell Biol., 39, 44 (2007).

6. P. Mecocci, J. Alzheimers Dis., 6, 159 (2004).

7. N. Singh, A.K. Dhalla, C. Seneviratne and P.K. Singal, Mol. Cell. Biochem., 147, 77 (1995).

8. P. Jenner, Ann. Neurol., 53, S26 (2003).

9. M. Boskovic, T. Vovk, P.B. Kores and I. Grabnar, Curr. Neuropharm., 9, 301 (2011).
10. V. Georgia, T. Dimitris and S. Christodoulos, Hellenic J. Cardiol, 50, 402 (2009).

11. P. Joshi and V. Dhawan, Curr. Sci., 89, 635 (2005).

12. A. Chaovanalikit and R.E. Wrolstad, J. Food Sci., 69, C67 (2004).

13. V. Dewanto, X. Wu and R.H. Liu, J. Agric. Food Chem., 50, 4959 (2002).

14. B. Bozin, N. Mimica-Dukie, N. Simin and G. Anackov, J. Agric. Food Chem., 54, 1822 (2006).

15. S. Iqbal, M.I. Bhanger and F. Anwar, Food Chem., 93, 265 (2005).

16. G.C. Yen, P.D. Duh and D.Y. Chuang, Food Chem., 70, 437 (2000).

17. M. Nasir, A.D. Sidra and Z. Mariyam, Int. J. Agro Vet. Med. Sci., 5, 322 (2011)

18. T. Mosmann, J. Immun. Methods, 65, 55 (1983).

19. L. Bravo, Nut Rev., 56, 317 (1998).

20. M.I.N. Moreno, M.I. Isla, A.R. Sampietro and M.A. Vattuone, J. Ethnopharmacol., 71, 109 (2000).

21. Y.Z. Cai, Q. Luo, M. Sun and H. Corke, Life Sci., 74, 2157 (2004).

22. A. Jain, M. Soni, L. Deb, A. Jain, S.P. Rout, V.B. Gupta and K.L. Krishna, J. Ethnopharmacol., 115, 61 (2008).

23. R. Kaur, S. Arora and B. Singh, Bioresour. Technol., 99, 7692 (2008).

24. S.M. Sabir and J.B.T. Rocha, J. Ethnopharmacol., 120, 226 (2008).

25. C. Yue, H. Bo, H. Jingsheng, H. Li, Z. Yichao and W. Youwei, J. Ethnopharm., 136, 309 (2011).

26. (a) B. Huang, X. Ban, J.S. He, J. Tong, J. Tian and Y.W. Wang, Food Chem., 120, 873 (2010); (b) B. Huang, X. Ban, J.S. He, H. Zeng, P. Zhang and Y.W. Wang, J. Ethnopharmacol., 131, 76 (2010).

27. A. Othman, A. Ismail, N.A. Ghani and I. Adenan, Food Chem., 100, 1523 (2007).

28. D. Ganjewala, S. Sam and K.H. Khan, EurAsian J. Biosci., 3, 69 (2009).

29. Z.K. Shinwari, I. Khan, S. Naz and A. Hussain, Afr. J. Biotechnol., 8, 7082 (2009).

30. P. Saha, S. Mandal, A. Das, P.C. Das and S. Das, Phytother. Res., 18, 373 (2004). 